\title{
The Impact of Distance Learning on Foreign Language Education
}

\author{
Liu Zhengxia \\ Faculty of Foreign Language Studies \\ Huaiyin Institute of Technology HYIT \\ Huai'an Jiangsu, PRC \\ liu4931520@126.com
}

\begin{abstract}
Distance learning (DL) involves some forms of learning that uses technology. Some educational researchers claim that DL based on digital technologies is changing the landscape of language learning. Foreign language online teaching is a new and rapidly development process, there are many challenges facing language professionals. It is expected that this DL mode will advance our understanding of the optimal design for online language learning in particular. The evaluation of DL format demonstrates its effectiveness in online language learning, and more importantly, in reinforcing the interconnection and interaction between instructors and learners.
\end{abstract}

Keywords-Distance learning; Language education; Learning process; Assessment

\section{INTRODUCTION}

Distance Learning (DL) involves some forms of learning by use of technology. Some educational researchers claim that DL based on digital technologies is transforming the landscape of learning.[9] DL is defined as learning that occurs in a context in which students are typically separated from their instructors on computer-based instructions, and the simplest definition of distance learning is learning in which students and teachers are separated by time and place by the use of video and audioconferencing and the Internet. DL was traditionally a response to barriers such as geographic remoteness or physical inability to participate in face-to-face classes by way of telephone, radio and television to facilitate production, distribution and interaction. Countries with large, scattered populations were also able to use methods of distance learning to provide education more widely as technologies were developed. However, none of these technologies have had the impact of distance learning on foreign language education today. Nowadays, all teachers are trained to learn effective strategies for distance learning to teach languages in access to any education institutions in the world.

\section{DEVELOPMENT OF DISTANCE LEARNING}

As teaching foreign language online is a new and rapidly evolving process, there are many challenges facing language professionals. Online language learning is conducted fully online, in which learners are separated from education providers and their peers by distance. However, in traditional face-to-face classroom instruction, poor classroom design and large lecture hall classes can harm the image and reputation of an institution, which proves to be deadly boring or ineffective. Distance learning courses, by contrast, are typically small with enrollments between 20 and 30 with effective instruction. It is expected that this DL mode will advance our understanding of the optimal design for online language learning in particular. [1

Distance learning (DL) for teaching second and foreign languages (L2) has only recently attracted the field's attention, primarily in response to student demand for: (i) greater scheduling flexibility unconstrained by time and place, and (ii) increased access to the less commonly taught languages (LCTLs)[2]. Distance language learning in lack of synchronous interaction is questioned by many instructors. Now with the development of technology, the deficiency can be adequately overcome by synchronous technologies such as audio and videoconferencing tools and live chat tools. Various sources of online language learning are available to learners, which also helps online language learning more effective and enjoyable. In a broader context of education, language instructors have witnessed the exponential growth of online education, especially since the emergence of Massive Open Online Courses (MOOCs)

As a result, online language instructors are confronted with many pressing issues, such as how online courses can be effectively designed to maximize its advantages over the traditional learning modes, and how online learners and instructors can interact effectively and how well online learners can collaborate with each other in an online environment. These issues are particularly relevant to language learning. However, insufficient support for interaction and collaboration has also long been recognized as an inherent issue in distance language learning when physical distance among the learners and between learners and teachers prevents effective personal interaction, despite the advances in technology[3]. 


\section{THE FRAMEWORK FOR DL APPROACH}

To date, only three major studies [4][5][6]have evaluated entirely online language courses on the basis of empirical data. In all cases, online learners are found to outperform students from conventional courses on the grammar output. The data from these studies verify that online language learning can be effective, at least as a means of improving writing, reading, and listening comprehension abilities. Nevertheless, it remains hard to determine which aspects of the online learning environment were responsible for these results. More research is necessary to find out the impact of DL approach on language learning. Thus, a framework of online learning is proposed to improve the language learning process.

\section{A. Methodology}

The foreign language learning program offered at HYIT (Huaiyin Institute of Technology) consists of four courses at three levels from the beginner to the advanced level. The participants, including the freshmen and sophomores, are divided into two groups: the experimental and control group. By use of the DL approach, students study online in collaborative and interactive environment without physical face-to-face contact with their teachers and peers. They will be evaluated on reading, writing, listening, and speaking proficiency for three stages, that is, at the beginning, the intermediate, and the advanced level, as shown in Table 1.

TABLE I LANGUAGE LEVELS OF ONLINE LEARNERS

\begin{tabular}{|l|l|l|l|l|}
\hline Courses & Reading & Writing & Listening & Speaking \\
\hline Beginning & 77.5 & 76 & 71 & 75 \\
\hline Intermediate & 82 & 88.5 & 80 & 89 \\
\hline Advanced & 88 & 90 & 89.5 & 90 \\
\hline
\end{tabular}

To further check students' understanding of the DL approach in learning language, instructors provide video lectures with synchronous interaction and collaboration in English and conduct online tutorials in the Collaborate classroom once a week for each course. For the beginner's courses, we allocate 2 hours for the weekly online class as we have more students at this level, whereas for the intermediate and advanced levels, we offer 1 hour weekly tutorials due to small enrolment numbers. The tutorial schedule is adapted to the distance learners' needs for both synchronous interaction and time flexibility as most of them are not required to commit their learning activities simultaneously.

\section{B. Analysis of Online Learning Process}

Many language learning models have been proposed in conventional education but few have been identified as to the needs of online learning. Conventionally, foreign language learning is defined as "a range of activities associated with better describing, understanding, supporting and guiding language practices and processes" [7]. The traditional face-toface classroom model focuses on the stimulate-response language education, which has been increasingly used recently in the application of educational technology for their online courses"[8]. In other words, it focuses on a learner-centred teaching and learning process, which emphasizes the impacts of educational technology on each phase of learning design, as shown in Table 2 . Table 2 summarizes the learning process, the tool(s) supporting each assessment, the mode of assessment, and the major learning focuses underlying learning activities. In designing these online learning activities, four elements are analyzed: a. The class design of distance learning for language learning, b. The emerging technologies and learning tools on line, c. The effective learning strategies for language education, d. Learners' and instructors perspectives on learning.

TABLE II ONLINE LEARNING PROCESS OF DL APPROACH

\begin{tabular}{|l|l|l|}
\hline Courses & Tools & Mode \\
\hline Reading & Audio-conferencing & Asynchronous Individual \\
\hline Writing & Wiki & Text exchange \\
\hline Listening & Collaborative classroom & Paired interaction \\
\hline Speaking & CMC & Keyboard chat \\
\hline
\end{tabular}

However, the DL approach appears promising in that many students respond favorably to the flexibility afforded by either computer-assisted language learning (CALL) or computermediated communication (CMC). $85 \%$ participants are related to their potential for self-directed learning and have their individual characteristics and learning styles. They acknowledge that the language learning process succeeds in the collaborative environment. The digital world allows them to do new things in new ways. But this potential can also be a double-edged sword: students learning language online have more freedom to be self-directed, but those students unable to direct their own learning are more liable to do poorly or simply drop out, as evidenced by the relatively low retention rates registered for DL courses in general [9]. As a whole, the experience using this approach enriches the task-based learning process and facilitates their language learning efficiency.

\section{Online Assessment of DL Approach}

Information and communication technologies (ICT) have helped to remove the isolation of learning at a distance and changed the nature of foreign language education. As a new emerging learning approach to teaching language, online assessments are also designed to support distance interaction and collaboration. A more detailed discussion on the types of assessments in the online program has been applied in the online assessment design.

TABLE III A DIAMOND MODEL BY LEAVITT

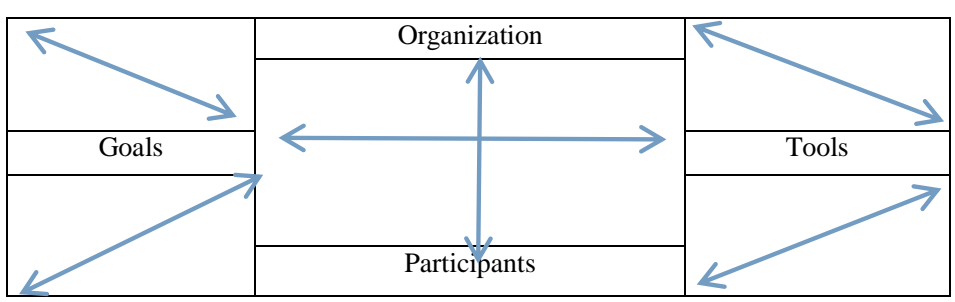

Leavitt (1965) developed a diamond model trying to show that changing any part of the system makes an impact on the other corners. It is important for the teachers/users to be involved in this process as soon as possible, preferably from the start. This ensures a better integration within the online 
process, and it makes the understanding of the online tools more obvious. The learning process is diverse, covering a range of educational backgrounds, while the assessments aim to promote both paired and group interaction and collaboration in completing written and oral tasks using online tools. The assessment revolves round a common theme of distance learning format. Thus, supporting and facilitating effective interaction and collaboration between learners and teachers is now becoming increasingly urgent as the distance learning technology has been ready and available. How it can be best designed for effective online learning is a challenge facing online language professionals.

The outcome data from these studies support the notion that the DL approach of learning language is an effective means in improving writing, reading, listening and speaking proficiency. Nevertheless, it remains hard to assess which aspect of learning environment is more effective.

\section{IMPLICATIONS AND CHALLENGES}

The implementing and evaluating of DL format in language education represent two separate issues: For the language instructors, careful class design is essential for online learning, and the classroom activities should be stimulating and initiative enough to arouse learning interests. For this reason, the online material should not clone the printed material and the creation of online curriculum is becoming more expensive and timeconsuming. On the part of language learners, the emerging technologies represent more challenges in avoiding the frustrations with the use of new technologies. It must be realized that not all language learners are ready to work independently and the enrollment of DL learners is limited to guarantee a sound learning environment as a wealth of students give up halfway and drop out of the course. Moreover, large enrollments in the DL format are as difficult to manage as in the conventional classroom. Finally, the greatest hurdle to generalizing findings about the DL approach to language education lies in the individual differences, which accounts for the major outcome variability and is hard to control. Although the DL approach has a significant contribution to change and influence the language curriculum, which will not be exempt from these trends. Further research is needed to demonstrate how DL approach help maintain the flexibility and feasibility in teaching foreign language and the field must provide DL instructors and curriculum developments with more insights on how the ICT medium can be used productively to foster language instruction.

\section{CONCLUSION}

As teaching and learning a foreign language in a DL mode is an innovative process with many challenges and new possibilities facing language professionals. The results suggest that well-designed DL instruction can offer a viable option for learners without access to the traditional classroom setting. In DL mode, language learning should be enjoyable and encourages lifelong learning in the changing world. The learning process is accelerated and adaptive with time flexibility and self-directed tutorial. Online learning can contribute to language learning, but much depends on the learning environment, materials, web-based class design and individual learners' differences.

The evaluation of DL format demonstrates its effectiveness in online language learning, and more importantly, in reinforcing the inter- connection and interaction between instructors and learners, which constantly feed into each other to form an interactive cycle of analysis, design, evaluation and improvement of language education. Nevertheless, the model is still generic, so it is far from complete and comprehensive. It is expected that this approach will advance our understanding of online language learning as an addition to the future of foreign language education.

\section{ACKNOWLEDGMENT}

Many thanks go to my partner---Professor Zhang, who gives me lot of academic help in the process of research. I also appreciate for his professional advice on my project. Besides, I am grateful for my school-- HYIT, which sponsors my research and ensures a comfortable research atmosphere to guarantee the completion of the research.

\section{REFERENCES}

[1] A. Carr-Chellman (Ed.), "Global perspectives on e-learning", Thousand Oaks: Sage Publications, 2005.

[2] R. Blake, and A. Delforge, "Online language learning: The case of Spanish without walls", in B. Lafford and R. Salaberry (eds.), Georgetown University Press, Washington, DC. 127-147, 2006.

[3] B. Smith, "Computer-mediated negotiated interaction: an expanded model” The modern language Journal, 87(1),38-57, 2003.

[4] D. Kennedy, and T. Duffy, "Collaboration--A key principle in distance education". Open Learning, 19 (2), 203-211,2004.

[5] K. Soo, and Y. Ngeow, "Effective English as a second language (ESL) instruction with interactive multimedia: The MCALL project", Journal of Educational Multimedia and Hypermedia 7(1), 71-89, 1998.

[6] S. Cross, and G. Conole, "Learn about learning design", Retrieved from http://cloudworks.ac.uk/index.php/cloud/view/1513, 2009.

[7] S.Carr, "As distance education comes of age, the challenge is keeping the students", The Chronicle of Higher Education, February 11, 2000.

[8] D.Cahill, and D. Catanzaro, "Teaching first-year Spanish on-line", CALICO Journal 14, 97-114.1997.

[9] V. Visser, and M. Visser-Valfrey, (Eds.)"Learners in a changing learning landscape:Reflections from a dialoguage on new roles and expectations.”, Dordrecht: Springer, 2008. 